\title{
El sistema misional en jaque: la reclusión femenina en las reducciones jesuíticas de guaraníes ${ }^{1}$
}

María Elena Imolesi*

Resumen: Este trabajo constituye una indagación acerca del cotiguaçú o espacio de reclusión de las mujeres en las reducciones jesuíticas de guaraníes. En este lugar se nuclearon, desde comienzos del siglo XVIII, mujeres de muy diversa procedencia y condición: viudas, huérfanas o cuyos hombres habían huido, así como traídas por los misioneros desde las zonas fronterizas pobladas por indios "infieles". En contraste con la escasa referencia al cotiguaçú en los escritos jesuíticos de circulación pública, la correspondencia reservada dedicaba minuciosas líneas a las disposiciones relativas a este espacio. Evidentemente el asunto revestía una gran importancia, pues el número creciente de recluidas y de hombres ausentes indica una tendencia a la desintegración familiar, a contrapelo de lo deseable en el espacio reduccional. Creemos por ende que este estudio contribuye a arrojar luz acerca de las crecientes tensiones dentro del espacio misional durante el siglo XVIII, en el contexto de una dinámica fronteriza luso-hispano-indígena inestable y de influencias permeables, en la cual se estaban generando procesos de dispersión, reconstrucción y etnogénesis que un espacio misional pretendidamente aislado se esforzaba por negar.

Palabras clave: Mujeres. Reducciones. Etnogénesis. Fronteras. Jesuitas.

* Licenciada en Historia. Doctoranda. Programa de Historia de América Latina. Instituto Ravignani. Universidad de Buenos Aires. E-mail: meimolesi@gmail. com. Dirección postal: Rivera Indarte 441 - $7^{\circ}$ C. CP 1406 - Ciudad Autónoma de Buenos Aires - Argentina 


\section{Introducción}

Este trabajo constituye una indagación acerca del cotiguaæú ${ }^{2}$ o espacio de reclusión de las mujeres en las reducciones jesuíticas de guaraníes. En este lugar se nuclearon, desde comienzos del siglo XVIII, mujeres de muy diversa procedencia y condición: viudas, huérfanas o cuyos hombres habían huido, así como provenientes de etnias de las zonas fronterizas (charrúas y de "guaraníes infieles", es decir, que no integraban el sistema de reducciones o que habían huido de él), traídas por los misioneros por la fuerza, o bien mujeres de los guenoas, (indios aliados de los jesuitas) y guaraníes reducidos, que buscaron amparo estacional en las misiones.

\section{Las ambigüedades del espacio femenino en las misiones ¿Cautiverio, reducción, protección o castigo?}

El cotiguazú reflejó una ambigüedad de propósitos: la declaración que en 1740 hizo el Padre Provincial Antonio Machoni (el cotiguaçú no es (árcel) ${ }^{3}$, es indicadora de que allí, a despecho de lo querido por las autoridades, se corporizaba el binomio castigo-protección en un mismo espacio. De hecho, pocos años más tarde, el superior de las misiones prescribía que se encerrase allí a las mujeres culpables de algún delito.

La casa de recogidas denota entonces dos aspectos complementarios: por un lado, el intento de disciplinamiento propio de las creencias y prácticas sociales vinculadas al lugar de la mujeres en sociedades patriarcales, potenciados por la idea de "reducir" a la vida cristiana propia del espacio misional, lo cual convertía al lugar en un encierro dentro del encierro que suponía el espacio misional. Por otro - el problema central de este trabajo - que consistía en la presencia de un número creciente de mujeres solas debido a la movilidad originada por los traslados de población por diversas causas, a las guerras con los portugueses o con otras etnias, a las huidas o al reasentamientos de los hombres, afectados a diversas obligaciones 
militares y laborales fuera de las reducciones. El intento de asegurar el contingente femenino respondía entonces a la necesidad de preservar al proyecto misional de la sangría demográfica en un contexto en el cual las mujeres escaseaban.

En contraste con la escasa referencia al cotiguazú en los escritos jesuíticos de circulación pública, la correspondencia reservada dedicaba desde la segunda década del siglo XVIII minuciosas líneas a las disposiciones relativas a este espacio. El asunto revestía una gran importancia, pues el número creciente de recluidas y de hombres ausentes indica una tendencia a la desintegración familiar, a contrapelo de lo deseable para las reducciones jesuitas. Creemos por ende que este estudio contribuye a arrojar luz acerca de las crecientes tensiones dentro del espacio misional durante el siglo XVIII, en el contexto de una dinámica fronteriza luso-hispano-indígena inestable y de influencias permeables, en la cual se estaban generando procesos de dispersión, reconstrucción y etnogénesis que un espacio misional, pretendidamente aislado, se esforzaba por negar.

Quiero hacer notar la ambigüedad del vocablo guaraní cotiguazú. Los misioneros lo traducían como "casa de recogidas" pero literalmente significa "casa grande" o "habitación grande", que es un significado bastante difuso para un lugar de reclusión femenina, que en este caso se produce dentro de otro espacio idealmente (aunque no efectivamente) cerrado que es el de las reducciones, con su utopía del aislamiento. El concepto de "reducir", presente en la legislación indiana, tiene una larga tradición y está presente por ejemplo, en las Leyes de Burgos de 1512, donde se establece que los indios deben ser reduzidos a pueblos. El término "reducir" remite a "persuadir" y "convertir" (MORALES, 2005, p. 30), en tanto someter a pautas de vida cristiana. En el diccionario español-latín de Antonio de Nebrija (1495) el término "reducir" remite a redigo que significa llevar a un estado o condición específicos (CUMMINS, 2007, p. 157).

Podría elegir lisa y llanamente la palabra "cautiverio" para definir la situación de las mujeres en el cotiguazú, ya sea que utilice el término en el sentido foucaultiano de encierro en tanto dispositivo de poder o, como lo hace Marcela Lagarde desde una perspectiva de género, como privación de la libertad, pero entendida como "categoría antropológica que sintetiza el hecho cultural que define el estado 
de las mujeres en el mundo patriarcal" (LAGARDE, 1990, p. 151). Sin embargo es el mismísimo Provincial jesuita Antonio Machoni quien en 1740 reconviene a sus subordinados, los misioneros a cargo de las reducciones, con tono severo: "el cotiguaçu no es cárcel”. Semejante aclaración no sólo indica que los niveles represivos habían sobrepasado lo esperable, sino la confusión reinante acerca de la finalidad del lugar.

La ambigüedad se relaciona directamente con la dificultad de definir situaciones muy variadas y no queridas o no declarables públicamente. De hecho, nuestra información principal proviene de la correspondencia privada y de los memoriales que los Padres Provinciales enviaban a los Superiores de las doctrinas del Paraguay. ${ }^{4}$

Las fuentes jesuitas tampoco acuerdan del todo con respecto a las características del cotiguazú. Pablo Hernández, en su clásico estudio sobre la organización social de las misiones jesuitas de guaraníes, refiere que la casa de recogidas era un edificio separado pero integrando el trazado inicial de los pueblos; sin embargo, no he hallado referencias acerca del mismo sino hasta $1714,{ }^{5}$ lo cual implicaría que durante algo más de un siglo de existencia de las misiones del Paraguay, este espacio no existió como tal.

Los estudios arqueológicos revelan que, en el caso del pueblo de Santa Ana (a orillas del río Paraná, en el actual territorio de la Provincia de Misiones, Argentina), el cotiguazú, en su actual materialidad, es una superficie de perímetro aproximadamente cuadrangular de $667 \mathrm{~m}^{2}$, que incluye un gran patio de 36 por 26 metros y 18 recintos (POUJADE; GUTIERREZ; AUSTRAL; ROCCHIETTI, 2008, p. 6).

Con anterioridad a la construcción de la casa de recogidas, sólo existía la cárcel para mujeres, en un edificio separado del de hombres, aunque a veces, según Hernández, en el mismo recinto del cotiguazú ("pero con separación de las personas que allí moraban”) (HERNÁNDEZ, 1913, p. 31-32). De hecho, tampoco parece que muy tempranamente se hayan construido cárceles, pues tanto el Provincial Agustín de Aragón en 1673 como el Provincial Tomás Donvidas en 1685, ordenaban la construcción de cárceles separadas de hombres y de mujeres, para los "delitos enormes y 
capitales", teniéndose por tales el homicidio y los delitos de tipo sexual, especialmente "si son contra naturam". 6

Como en el resto del conjunto reduccional en general, la rutina diaria en el cotiguazú también implicaba una parcelación del tiempo, como lo describía el padre José Cardiel:

[...] las mujeres de la casa de Recogidas, se les obliga que vengan en comunidad con sus alcaldes viejos a Misa y rosario y demás funciones eclesiásticas, como vísperas solemnes, etc. En lo demás del tiempo están ocupadas en sus labores mujeriles de hilar, coser y de traer agua y leña para su recogimiento. (FURLONG, 1953, p. 174)

Es necesario aclarar que lo que el jesuita describe como "labores mujeriles" de hilar era uno de los pilares económicos de las misiones, y ocupaba a todo el universo femenino de las reducciones, no sólo a las recluidas. El misionero Anton Sepp refiere que, hacia 1700, sólo en un año, las indias del recién fundado pueblo de San Juan habían hilado 20.000 varas $^{7}$ de tela, de las cuáles se destinaban dos tercios para vestir a 14.000 indios y el tercio restante se comercializaba en el puerto de Buenos Aires. Con el producto de la venta se pagaba el tributo de los indios y se compraban elementos necesarios en las misiones (SEPP, 1973, p. 31).

En 1672, el Provincial Aragón prescribía que no se ponga a las mujeres a hilar en público como castigo. ${ }^{8}$ Sólo un año más tarde, el nuevo Provincial Cristóbal Gómez ordenaba que "no se les castigara por el hilado con azotes, cepo, ni Grillos", ${ }^{9}$ prescripciones que mostraban que el incumplimiento de la tarea de hilar el algodón era objeto de sanciones severas.

\section{El cautiverio de las mujeres indígenas en Hispanoamérica}

El modelo jesuita de reclusión femenina fue iniciado en la Casa de Santa Marta, fundada por Ignacio de Loyola en Roma en 1543, 
lugar de refugio de prostitutas que decidían abandonar su oficio y pasaban a ser conversae (reformadas o convertidas) cuyos destinos posibles eran el servicio doméstico, el matrimonio o la vida religiosa. De hecho, en 1573 Santa Marta se convirtió en convento de pleno derecho, reservado para vírgenes, mientras que las prostitutas reformadas quedaron en la "Casa Pía” (O’ MALLEY, 1993, p. 223-233).

También fundó Ignacio en Roma a mediados del siglo XVI un Conservatorio para recoger niñas de entre 10 y 12 años, hijas de prostitutas, llevadas allí voluntariamente por sus madres. Este modelo se trasladó a territorios coloniales. A fines del siglo XVI el obispo agustino Fray Luis López de Solís fundó en Quito la casa pía de Santa Marta, en donde, según el Provincial jesuita Joseph de Arriaga, "encierran en recogimiento por fuerça a las indias perdidas" que de allí "salen casadas y enmendadas". ${ }^{10}$ Esto incluía recoger mujeres que no vivían con sus maridos a causa de los maltratos recibidos o a las que estaban amancebadas con españoles.

Sin embargo, los jesuitas no inventaron, como sabemos, la reclusión femenina. Para remitirnos sólo al espacio americano y a las indígenas: las ordenanzas generales para pueblos de indios del virrey Francisco de Toledo establecían que las indias mozas, viudas y solteras, "que en los repartimientos hay gran cantidad [...] las cuales les dan mal ejemplo a otras", si no pudiesen vivir con sus padres u otros parientes, sirviesen en casa de indios casados (TOLEDO, 1989, p. 261). Es decir que se distribuiría a las mujeres solas en casas de familia destinándolas al servicio doméstico. La idea predominante (y esto en consonancia con lo esperado para el universo femenino en general) era que las indias que se hallaban solas constituían un peligro para sí y para la moral del grupo en general y que por ende debían estar confinadas al ámbito doméstico. Por el mismo motivo se dispuso que no debían ir a las minas sino sólo las casadas y con sus maridos y que su tarea bebía limitarse allí a servir a sus maridos y guisarles la comida. Los jesuitas a cargo de la doctrina de Juli (Perú) informaban que las mujeres eran llevadas allí por sus maridos cuando éstos debían ausentarse para cumplir con la mita. ${ }^{11}$

En el marco de entornos misionales y en áreas de frontera, Catherine R. Ettinger, ha estudiado los llamados "monjeríos" en las misiones de la Alta California (ET'TINGER, 2010), adonde los 
franciscanos llegaron en 1769, poco después de la expulsión de los jesuitas. Como parte misma de las estrategias en la cristianización y europeización de la población, los frailes franciscanos implementaron en la Alta California un programa de construcción de vivienda que permitiría tener mayor control sobre la población con la intención de modificar costumbres y modo de vida. Fragmentaron los núcleos familiares y los repartieron en distintas unidades de vivienda. Las niñas mayores de 6 o 7 años, las viudas y las solteras, eran asignadas a una habitación dentro del cuadro de la misión llamada monjerío. Allí pernoctaban bajo llave. La función de "llavera" era también ejercida por una mujer.

Como sucede con el cotiguazú jesuítico, existen también algunas contradicciones en la información acerca de los monjeríos. Difieren las versiones de los comandantes de frontera y de los frailes. En la defensa del sistema misional, estos últimos describen los espacios como bien ventilados y limpios. Comandantes y visitantes concuerdan en su mal estado y suciedad. Sin embargo y a pesar de las pésimas condiciones de vida en estos espacios, representaban una opción atractiva para mujeres que veían su vida tradicional desmoronarse. Afuera de la misión, estaban vulnerables a la violencia. Son varios los autores que tratan el tema de la violencia contra la mujer en el contexto de las misiones californianas (COOK, 1976; JACKSON; CASTILLO, 1995). Ante este escenario de vulnerabilidad femenina y disolución social, la garantía de integridad física y sustento alimenticio serían incentivos para ingresar a la vida misional (E'T'TINGER, 2002, p. 86-92).

Como el monjerío de la California franciscana, el cotiguazú del Paraguay jesuítico es una institución propia de una frontera móvil y esta similitud convoca a alguna reflexión. Propongo considerar el cotiguazú como una institución de frontera, funcional a un área de transferencias y de influencias recíprocas, donde los intercambios interétnicos, la movilidad espacial, las guerras y sangrías demográficas, los cambios ecológicos (con la introducción del ganado vacuno y la competencia que se generó por el mismo) y la competencia entre las potencias generó conflictos en los cuáles la mujeres, como capital reproductivo, se volvían cruciales. 


\section{Algunas interpretaciones sobre la reclusión de las mujeres en el cotiguazú}

Eliane Deckmann Fleck, basada especialmente en el célebre texto de Antonio Ruiz de Montoya ${ }^{12}$ y en las cartas anuas de la Provincia del Paraguay nos muestra una construcción discursiva bastante monolítica y sin fisuras acerca de lo femenino en las misiones que respondía a la mirada de los misioneros o, para ser más precisos, a lo que éstos podían o deseaban hacer público. La única referencia al cotiguazú es la siguiente: "Devido às fugas dos maridos polígamos e ao repúdio às primeiras mulheres, geralmente mais velhas, resultou um grande número de mulheres abandonadas que foram encaminhadas ao 'cotiguazu"' (FLECK, 2006). ${ }^{13}$

Es llamativo el contraste si analizamos la correspondencia reservada que mantenían los jesuitas entre sí, la cuestión es bastante más compleja: las mujeres no son ya ni "mancebas del demonio" ni "devotas congregantes" (arquetipos que Fleck considera propios de las representaciones jesuitas sobre la mujer indígena) sino el signo y el resultado más claro de un serio problema a resolver: el incremento de las migraciones, incluida la entrada de nuevas familias procedentes del exterior del entorno misional, de la violencia, y de la disolución familiar.

La primera referencia al cotiguazu la he hallado en el memorial del Padre Provincial Luis de la Roca en 1714:

[...] hágase una buena casa, fuerte y capaz, con su patio y divisiones para las Viudas, Solteras y Huérfanas; y en una división se pondrán las Viudas y las que tienen ausentes sus maridos; en otra las Solteras y Huérfanas... ${ }^{14}$

Los libros de órdenes, que los superiores jesuitas redactaban tras sus periódicas visitas a las reducciones, otorgaban gran importancia al mantenimiento del cotiguazú o casa de recogidas, del cual no tenemos noticias hasta entrado el siglo XVIII. Tanto en las Instrucciones de 1722 como en las de 1724 los Provinciales insisten en el buen estado edilicio y normas precisas de encierro e incluso 
de alimentación de este espacio en donde se hallaban las viudas, las huérfanas y las que habían sido abandonadas por varones que habían huido o bien quienes por diversas circunstancias no habían retornado a sus respectivos pueblos. Así lo expresaba el Padre Provincial en 1722:

Para que las recogidas del Cotiguazu lleven con suavidad y gusto el encerramiento se procurará acabar la casa nueva [...] Porque con el tiempo se aumentará el numero de las recogidas [...] se les hará el corralito según está encargado [...] Para que las recogidas esten contentas y con alivio en su encerramiento se les assistirá en la comida con más liberalidad mandándoles matar por lo menos tres vacas cerca del cotiguazu porque necessitan mas comida de la que asta ahora se les ha dado, por haver muchos chiquillos con sus madres. ${ }^{15}$

Lo primero que me sugiere esta prescripción es en la idea de reproducir un ámbito doméstico de calidez en un lugar donde madres e hijos conviven, como en los espacios carcelarios (LAGARDE, 1997, p. 679). Ahora bien, ¿cuál era el origen de éstos niños? Las fuentes no ofrecen precisiones. Mayoritariamente deben ser los hijos de las mujeres que han quedado solas en los pueblos por las salidas, muertes o huidas de sus maridos; sin embargo, está claro que habían diferentes procedencias, pues podía tratarse de contingentes de mujeres y niños provenientes de zonas conflictivas de guerra en territorios fronterizos: charrúas traídos a la fuerza o guenoas venidos voluntariamente (BRACCO, 2004, p. 361). A diferencia de los charrúas que se aliaron a portugueses y españoles en contra de la sociedad jesuítico-guaraní, los guenoas del oriente del río Uruguay, dueños de una gran reserva ganadera, en general mantuvieron ocasionales alianzas con los jesuitas y llevaron a sus mujeres y niños a las reducciones, en donde parte considerable de estos contingentes quedaron, por voluntad o necesidad de los indios, dentro de las reducciones. Esto estaría mostrando la iniciativa indígena, condicionada ciertamente por la situación, de ingresar en las reducciones para obtener protección, como hemos visto que habría sucedido en el caso de las misiones californianas. 
Dos años más tarde, el nuevo Provincial, Luis de la Roca, insistía en los mecanismos detallados del confinamiento y también en la separación de los diversos grupos de mujeres:

Para que aya uniformidad en el govierno de las Recogidas se observara lo siguiente: Primero iran juntas alabar a las funciones de regocijo del pueblo a las prosesiones de entre año y Semana Santa a los Exemplos Rosario y demas funciones de la Iglesia. Segundo, saldran a leñar juntas, en donde no huviere inconveniente y en donde lo huviere se les proveera con abundancia de leña, [que] no se obligue [al recogmiento de] las casadas que viven sin notas, ausentes sus maridos ni a las solteras que tienen Padre o madre [...] la puerta de la calle ha de tener dos llaves de guardas diferentes de las quales tendran de noche una el Padre Cura y otra la Madre o vieja que cuide de ellas y esta solo abrira por adentro como la otra por afuera. [...] Ayga campanilla que caiga al aposento del viejo pero este no tendra ventana que caiga a la casa de las recogidas, mas esta ventana se podra permitir con tal que se sierre con llaves por la parte de dentro de d.ha Casa de Recogidas, la qual llave estara en poder de la madre de ellas quien podra abrir quando las quieren ver sus parientas. [...] Si no tuvieren Casas distintas las viudas y huerfanas, vivieran por lo menos separadas estas de aquellas en distintos aposentos. ${ }^{16}$

Como podemos observar, las prescripciones de aislamiento son prácticamente conventuales y se insiste en ellas con todo detalle, incluyendo la prescripción de separar en el interior de la casa a mujeres con distintas situaciones vitales. Asimismo se castigaría a los que entrasen en el cotiguazú "para el trato ilicito con ellas" con 25 azotes y exposición "para la verguenza" en los dos pueblos mas cercanos. ${ }^{17}$

Todavía a fines de la época jesuítica se insistía en la importancia de construir o mejorar las casas de las recluidas. En 1756, el Superior solicitaba que se emprendiese "cuanto antes" la construcción de la casa de recogidas en la reducción de Santiago, tanto como lugar de 
reclusión "para las que merecen algun castigo por sus delitos" y como "para aquellas que para vivir con mayor seguridad lo pidieron". ${ }^{18}$ Pareciera que, en la percepción del Superior, los índices de penas criminalizables y la inseguridad en los pueblos había aumentado, pues previo a esta fecha no hay noticia de que el cotiguazú fungiera de cárcel.

Que los niveles de represión sobrepasaban lo aceptable por las autoridades jesuitas parece claro en las instrucciones del Provincial Antonio Machoni, veinte años después de las de su antecesor de la Roca. En 1740, advierte a los misioneros que "el cotiguazú no es cárcel". Reitera los cuidados que deben tenerse en la comida y vestidos, sobre los que ha habido quejas, que no debieran existir porque los misioneros deberían socorrer al cotiguazú con la producción del tupambaé (tierra de producción comunal). En un escrito realmente muy duro y que denota preocupación, insiste en que los castigos deben moderarse: "si el Misionero excede en los Castigos, no hay cosa mas encomendada; (y lo ordeno de nuevo) que sacarlo de las Misiones, si no bastan los avisos". ${ }^{19} \mathrm{Y}$ en seguida advierte sobre los castigos rigurosos, especialmente a las embarazadas, cuya penalización, y sólo en caso de delitos graves, deberá realizarse después del alumbramiento. El comentario que hace a continuación indica que los misioneros se extralimitaban en el lapso y rigor de los castigos con "la futil excusa de que [las indias] han de volver a caer o huirse; y en caso de reincidir se ejecutará lo que poco ha dije". ${ }^{20}$ Ya décadas antes las autoridades jesuitas daban cuenta de la existencia de "muchos abortos por los castigos de las indias". ${ }^{21}$

\section{El cotiguazú como indicador de inestabilidad y conflicto del sistema de reducciones con el entorno}

¿Qué hay detrás de estos “excesos” señalados por Machoni? Las cuestiones disciplinarias hacia las mujeres en las reducciones, acerca de cuyos objetivos generales hemos escrito en la primera parte de este trabajo, revelan por un lado, la distancia entre lo real y lo deseado por los misioneros, pero además, la presencia de un número creciente de mujeres "solas" aparece como una cuestión 
que preocupa a los jesuitas desde la segunda década del siglo XVIII. En el mismo Memorial arriba citado el Provincial insiste en la urgencia de casar a los jóvenes que estén en edad casadera, así como a los viudos y viudas. Entendemos que el problema reviste la mayor importancia, pues el número creciente de recluidas indica que proliferaban las mujeres solas y que las familias tendían con frecuencia a desintegrarse. Los misioneros declaran que había muchos huérfanos porque sus madres morían y no había quien los alimente. Ante esto se sugería darlos a alguna mujer para que los críe, proveyendo a ésta de mayores recursos.

La falta de hombres era provocada tanto por el mismo sistema misional como por la situación de frontera. A causa de la alianza entre los guaraníes reducidos y el poder español, los indios estaban afectados al servicio militar (tanto para luchar con los portugueses como contra etnias indígenas “infieles") y laboral (salidas a la Vaquería de Mar, ${ }^{22}$ que se prolongaban durante meses, para arrear decenas de miles de reses o bien tareas de construcción en el lejano puerto de Buenos Aires, por citar sólo algunos ejemplos) lo cual generaba permanentes salidas de contingentes masculinos de los pueblos. Al mismo tiempo, tratar de asegurar a las mujeres responde a un contexto de crónica y creciente amenaza de déficit femenino. El cotiguazú, entonces, no sólo es un dispositivo de disciplinamiento, sino que responde a un objetivo de alcances mas urgentes aún: la necesidad de preservar al proyecto reduccional de la sangría demográfica en un contexto en el cual la mujeres escasean.

De hecho el memorial de Machoni coincide con el pronunciado declive demográfico en los treinta pueblos desde 1730. Este obedeció a varias causas: las sucesivas epidemias de viruela durante la década de 1730 (la población de las misiones disminuyó a la mitad durante este periodo), la participación de soldados guaraníes en los enfrentamientos contra los portugueses o bien contra los colonos del Paraguay en la Revuelta de los comuneros (guerra civil que se desarrolló entre las décadas de 1720-30). Las epidemias no sólo aumentaban las tasas de mortalidad sino que disminuían los nacimientos y ocasionaban huidas de los pueblos. La esperanza de vida al nacer descendió de 34,8 en 1727 a 8,8 en 1732 y a 0,2 en 1737 , para volver a recuperarse a 20,1 y 23,0 en la década siguiente. 
Robert Jackson, que alude a la importancia del cotiguazú como reservorio poblacional, menciona que la recuperación demográfica fue relativamente rápida en las reducciones del Paraguay debido a la más alta cantidad de población en comparación con las misiones del norte de México, cuya tendencia declinante no pudo revertirse. (JACKSON, 2004, p. 140-150).

En el caso de los pueblos guaraníticos, el Tratado de Madrid de 1750, que determinaba la entrega de siete de las treinta doctrinas de guaraníes a los portugueses, ocasionó el traslado de 29.000 indígenas fuera de sus pueblos (WILDE, 2009, p. 157) y por ende un nuevo declive demográfico. Aunque el Tratado se anuló, la población guaraní, que se resistió a entregar sus pueblos originando lo que se conoce como guerra guaranítica, sólo se reintegró a los pueblos parcialmente, habiéndose reducido en 1756 a la mitad, con respecto a la existente al comienzo de la guerra.

Que los indígenas consideraban el cotiguazú como un símbolo de opresión quedó claro en el accionar de los líderes de la guerra guaranítica, que como primera medida inmediata a la toma del pueblo de Yapeyú, liberaron a las mujeres del cotiguazú (MORALES, 2007, p. 217).

\section{$\mathrm{E}$ l cotiguazú y los conflictos interétnicos en un área de frontera difusa}

Las fuentes jesuíticas no presentan mayores precisiones sobre al origen de las mujeres confinadas. En los últimos años se ha publicado información que permite tener un cuadro de situación mucho más completo respecto a la procedencia de las mujeres y a los procederes de los jesuitas (BRACCO, 2004; WILDE, 2009). Las culturas "infieles" de las áreas limítrofes con los guaraníes, particularmente al sur y al este de los 30 pueblos, por ejemplo, las del actual territorio uruguayo (guenoas, charrúas) colapsaron en buena medida por la desaparición de sus mujeres. Dentro de estos grupos insumisos se incluyen también a los llamados "guaraníes infieles", o indígenas huidos de las reducciones o jamás asentados 
en ellas y que secularmente se habían refugiado en el territorio de la Banda Oriental. La dificultad de obtener un panorama claro de lo sucedido con toda esta población se acrecienta porque la categoría de "infiel" se utiliza en la época de un modo bastante ambiguo para hacer referencia a la movilidad, la no pertenencia y, sobre todo, la oposición al orden establecido (WILDE, 2003).

El odio de los charrúas hacia los jesuitas nació de la captura que hacían los religiosos de sus mujeres para llevarlas a las misiones y eventualmente casarlas con guaraníes. Las incursiones que partiendo desde el pueblo de Yapeyú se adentraban en territorio "infiel”, que invariablemente terminaban en masacres y apropiación de mujeres para relocalizarlas en las reducciones, se produjo dentro de un contexto de verdadera guerra de exterminio impulsada por los jesuitas en contra de esta nación a la que consideraban irrescatable, tanto por las incursiones que estos indios hacían para obtener ganado de la Vaquería de Mar, como por su alianza con los portugueses. En 1702, tras el combate de Yi (en el centro de la actual República Oriental del Uruguay) entre españoles y charrúas, los jesuitas (principales instigadores del enfrentamiento armado) a cargo de un bien pertrechado ejército de guaraníes reducidos, se encargaron de apresar y trasladar a un contingente de unas quinientas mujeres y niños que destinaron a las misiones (BRACCO, 2004, p. 232-233). El Padre Juan Bautista Zea, quien se encargó de conducir este contingente a las reducciones declara tajante: "que se reduzcan a la fe en pueblo fijo y determinado [...] pero si esto no se consigue, que lo dudo mucho de gente tan fiera y barbara, mejor sera que pasen por los mismos filos que sus parientes". 23

La decisión de los jesuitas de no tolerar a los indios insumisos no era un secreto y se fundaba en la distinción que éstos realizaban entre lo que consideraban posible y lo imposible, frontera vinculada a una clasificación cultural, pero que se fundaba a su vez en la experiencia misional concreta. El jesuita José Cardiel refería el levantamiento de todas las "naciones de infieles de a caballo" contra las misiones en 1713-14. El misionero menciona a yaros, charrúas, guenoas y minuanes 24 "tratando continuamente de su conversión, aunque con poco fruto por ser de a caballo y sin sementeras perpetuas, vagamundos como tártaros, árabes y gitanos, y por tener comercio con los 
españoles” (FURLONG, 1953, p. 158). Cardiel describe que cerca de los charrúas había un "gran número" de guaraníes huidos de las reducciones, que morían sin confesión ni sacramentos, como infieles. Interrogados acerca de la decisión de no retornar a las reducciones, los indios refirieron - al decir del misionero - que ya se habían desacostumbrado a trabajar las sementeras y a ser obligado a ello con castigo.

Es muy posible que estos contingentes de mujeres llevados a las misiones después del combate de Yi (1702) expliquen la importancia que se le empieza a dar al cotiguazú. Otra fuente de entrada de mujeres fueron las originarias de los guenoas, ocasionales aliados de los jesuitas en su lucha contra los charrúas: muchas de sus mujeres buscaron amparo estacional en las misiones, donde se las persuadió para no volver. Desde fines del siglo XVII algunas parcialidades guenoas se habían ido convirtiendo e integrándose al pueblo de San Miguel, con cuya colaboración contaron en cuanto a recibir algunas tierras para asentarse. ${ }^{25}$ La negociación de mujeres, incluso con sus propias familias, eran parte de los tratos entre los misioneros y los caciques guenoas. En 1683, el Padre Francisco García, a cargo de la reducción de Santo Tomé, escribió al Provincial que habiendo logrado congregar una parcialidad de guenoas, hizo llamar al cacique principal "para que me diesse una hermana, con su marido, y tres o cuatro hijos", a lo cual el cacique respondió que cuantos indios quisiesen podrían quedar en la reducción, como lo habían hecho hasta ese momento (BRACCO, 371).

La idea de que las misiones de la frontera sur de los treinta pueblos se convirtieron en un reservorio poblacional está avalada por los datos demográficos. Durante la primera mitad del siglo XVIII, mientras que la mayoría de las reducciones jesuitas de guaraníes ven disminuir su población o bien experimentan un leve crecimiento, Yapeyú, la más meridional de las reducciones, casi triplicó su población en este periodo, (de 2.206 habitantes en 1702 a 6.187 en 1744) convirtiéndose en la reducción con mayor aumento demográfico y con mayor cantidad de población en términos absolutos. (JACKSON, 2004, p. 164). 


\section{Consideraciones finales}

Hemos intentado reconstruir la historia de un espacio socialmente destinado al confinamiento de las mujeres dentro de otro espacio artificial como lo fue el de las reducciones jesuitas de guaraníes. El mero hecho de que el trazado inicial no tuviese previsto este espacio es un indicador de que algo no había salido según los planes.

Allí se verificaron todas las situaciones por las cuáles el poder consideraba necesario enclaustrar a las mujeres: desde preservar su virginidad y/o su castidad, al tiempo que se castigaban las conductas "impropias", esecialmente las sexuales. Pero también se buscaba preservar el capital reproductivo en tanto se posibilita que queden amparadas las mujeres que ya son madres pero han perdido a su pareja y las que eventualmente podían ser madres en un futuro. Al mismo tiempo se mantenía el capital productivo de las reducciones, pues a las mujeres, como hemos visto, se debía la producción de hilados de algodón.

Las mujeres allí recluidas no han dejado testimonios. Los sacerdotes tampoco quieren hablar abiertamente de lo que allí sucede. Sin embargo, el lugar es un indicador, y muy fuerte, de la situación compleja de una frontera colonial en la cual indios, portugueses y españoles compiten y al mismo tiempo se fusionan. El cotiguazú fue una institución funcional a la situación de la frontera, en donde, como apunta Guillaume Boccara "si bien los agentes coloniales sabían lo que hacían y porqué lo hacían, no pudieron medir las consecuencias de lo que hacían" (BOCCARA, 2001, p. 26). El cotiguazú acompañó a los procesos de etnogénesis ${ }^{26}$ de la región, y con su existencia intentó evitar y al mismo tiempo negar estas interacciones que el poder colonial no deseaba o no podía reconocer. Frente a la utopía del aislamiento, propia del sistema de reducciones, el cotiguazú es todo un símbolo de las contradicciones y de la imposibilidad de lograrlo. Fue la misma dinámica del sistema colonial, con su tasa de masculinidad mermada por traslados, muertes en guerras, etc., la que favoreció el desmembramiento de la familia que el propio sistema intentaba defender. 


\section{THE MISSIONS SYSTEM AT STAKE: THE COTIGUAZÚ AS A SYMPTON OF THE JESUITS- GUARANI REDUCTIONS CRISIS}

Abstract: This paper aims at exploring the cotiguazú, an area of seclusion for women in the jesuits - guarani reductions. Many women of different backgrounds (widows, orphan girls, women whose men had run away as well as women brought by the missionaries from areas inhabited by not christianized indians or "infieles") were gathered in this space since the XVIII century. In contrast to the few references about the cotiguazu in the jesuits public documents, the private correspondence offers detailed information about the regulations regarding this space. The issues about the cotiguazu were of great concern since the increasing number of women secluded there, indicates the desintegration of the family institution. This evidence shows an opposite tendency to what was desired in the missional space. This investigation tries to explore the growing tensions within the missions during the XVIII century as a result of the unstable dynamics of the portuguese-spanish-indian border. These were causing the scattering, reconstruction and ethnogenesis that the supposedly isolated missions were trying to deny. Keywords: Women. Missions. Ethnogenesis. Borders. Jesuits.

\section{Notas}

${ }^{1}$ Versión corregida y ampliada del trabajo presentado en el Coloquio Internacional Tradiciones indígenas y culturas misionales en las fronteras la Sudamérica colonial, Buenos Aires, 17 y 18 de agosto de 2011.

${ }^{1}$ Em espanhol: $O$ cotiguacún.

${ }^{2}$ Memorial del Padre Provincial Antonio Machoni para el Padre Superior de estas Doctrinas del Parana y Uruguay y sus consultores, en la Visita de 29 de Junio de 1740. BNM, Ms 6976, f. 286.

${ }^{3}$ Véase Morales, Martín, op. cit. y Biblioteca Nacional de Madrid, Ms 6976. Agradezco el acceso al Manuscrito a la copia que me facilitó el Padre Martín Morales SJ. ${ }^{4}$ Memorial del Padre Provincial Luis de la Roca SJ en la visita del 3 de agosto de 1714 para esta doctrina de los Santos Apóstoles. AGN, Sala IX, 6-9-5.

${ }^{5}$ Carta del P. Provincial Agustin de Aragon a los Padres Missioneros su fecha 8. de Maio de 1672. BNM, Ms. 6976, f. 81-82. Carta del Prov. ${ }^{\mathrm{L}}$ thomas Donvidas de 10. de Diziembre de 1685. A los Misioneros del Parana, y Uruguay, BNM, Ms. 6976 , fs.131-132. Los delitos contra natura (homosexualidad, bestialismo e incesto) eran considerados penas capitales.

${ }^{6}$ Según el Diccionario de la Real Academia Española, una vara equivale a 7,72 m.

${ }^{7}$ Carta del P. Provincial Agustin de Aragon a los Padres Misioneros. 8 de Mayo de 1672, BNM, Ms 6976, f. 82 
${ }^{8}$ Carta Comun a todas las Doctrinas del Pe. Cristóbal Gomez Provincial de esta Provincia. Doctrina de Santiago, 4 de Junio de 1673. BNM, Ms. 6976, f. 93.

${ }^{9}$ Carta Anua de la Provincia del Perú (1597). El P. Joseph de Arriaga al Prepósito General Claudio Aquaviva. En Egaña, Antonio de, Momumenta Peruana, VI, p. 306. ${ }^{10}$ Anua de 1632, 1633 y 1634, ARSI, Per 15, f. 47 v.

${ }^{11}$ Montoya, Antonio Ruiz de, Conquista espiritual hecha por los religiosos de la Compañia de Jesús en las provincias del Paraguay, Paraná, Uruguay y Tape [1639] Bilbao, Imprenta del Corazón de Jesús, 1882.

${ }^{12}$ Yo misma he advertido sobre este tipo de discurso misional acerca de las mujeres en "La Roma del Perú": costumbres sexuales, clasificación cultural y perspectivas misionales en los textos jesuitas". Grupo de Estudios de Religiosidad y Evangelización. I Jornadas de Estudios sobre religiosidad, cultura y poder. Buenos Aires, 12 de noviembre de 2004.

${ }^{13}$ Memorial del Padre Provincial Luis de la Roca en la visita del 3 de agosto de 1714 para esta doctrina de los Santos Apóstoles. AGN, Sala IX, 6-9-5.

${ }^{14}$ Memorial del Padre Provincial Joseph de Aguirre en la Visita a las doctrinas del Paraná y Uruguay, enero de 1722, AGN IX, 6-9-5, f. 923,925 y 933.

${ }^{15}$ Ordenes del Provincial Luis de la Roca para las Doctrinas del Parana y Uruguay en la visita de 1724, BNM, Ms. 6976.

${ }^{16}$ Loc. cit.

${ }^{17}$ Instrucciones del Padre Superior Antonio Gutiérrez, 1756. AGN, IX, 6-10-1, f. $1081 \mathrm{r}-\mathrm{v}$ y f. 1066.

18 Memorial del Pe. Prov.l Antonio Machoní para el Padre Superior de estas Doctrinas del Parana y Uruguay y sus consultores, en la Visita de 29 de Junio de 1740. BNM, Ms 6976, f. 286.

${ }^{19}$ Ibidem, f. 287

${ }^{20}$ Carta del Padre Provincial Tomás de Baeza. 15 de Abril de 1682, para los Misioneros del Parana y Uruguay. BNM, Ms 6976.

${ }^{21}$ Fuente de abastecimiento de ganado de las estancias jesuíticas. En la costa sudeste de la Banda Oriental.

${ }^{22}$ Carta del P. Juan Bautista Zea al Gobernador Prado Maldonado, Santo Tomé, 12/03/1702. AGN, IX 41-1-3

${ }^{23}$ Bracco señala que guenoas y minuanes son denominaciones de un mismo grupo, correspondiendo el primer apelativo a los jesuitas y el segundo a los españoles.

${ }^{24}$ Carta del Padre Provincial Gregorio de Horozco, 6 de Febrero de 1689, BNM, Ms 6976, f. 148.

${ }^{25}$ Los procesos de etnogénesis se definen como modalidades por medio de las cuales surgen nuevos grupos humanos a nivel local. Wilde, Guillermo. Religión y poder..., p. 54. Guilleume Boccara los define como "procesos muy diversos de 
transformaciones no solamente políticas sino que también en las formas de definición identitarias de un mismo grupo a través del tiempo". Boccara, op. cit., p. 14.

\section{Referencias}

BOCCARA, Guillaume. Mundos nuevos en las fronteras del Nuevo Mundo In: Nuevo Mundo Mundos Nuevos, Debates, 2001. Disponível em: < http:/ / nuevomundo. revues.org/426>. Acesso em: 08 de fev. 2005.

BRACCO, Diego. Charrúas, guenoas y guaranies. Interacción y destrucción: indígenas en el Río de la Plata. Montevideo, Linardi y Riso, 2004.

COOK, Sherburne. The Conflict between the California Indians and White Civilization. Berkeley, University of California Press, 1976.

CUMMINS, Tom. Formas de las ciudades coloniales andinas, libre albedrío y matrimonio, In: SIRACUSANO, Gabriela (Ed.). Las tretas de lo visible, Buenos Aires, CAIA, 2007.

ETTINGER, Catherine R. Aculturación y Arquitectura; los Espacios de Habitación para las Mujeres en las Misiones de la Alta California. In: Revista Géneros, Universidad de Colima, año 10, n. 28, oct. 2002.

Una nueva domesticidad. Los indígenas de la Alta California y la vivienda misional, Nuevo Mundo Mundos Nuevos, Debates, 2010. Disponível em: <http:// nuevomundo.revues.org/58264>. Acesso em: 05 de jan. 2010.

FLECK, Eliane Cristina Deckmann. De mancebas auxiliares do demônio a devotas congregantes: mulheres e condutas em transformação (reduções jesuítico-guaranis, séc. XVII). Revista Estudos Feministas, Florianópolis, v. 14, n. 3, p. 617-634, Sept./ Dec. 2006.

FURLONG, Guillermo. José Cardiel SJ y su Carta Relación (1747). Buenos Aires: Librería del Plata, 1953.

HERNÁNDEZ, Pablo S. J. Organización social de las doctrinas guaranies de la Compañía de Jesús, I. Barcelona: Gustavo Gili, 1913.

JACKSON, Robert; CASTILLO, Edward. Indians, Franciscans and Spanish Colonization: the impact of the mission system on California Indians. Albuquerque: University of New Mexico Press, 1995.

JACKSON, Robert H. Una mirada a los patrones demográficos de las misiones jesuitas de Paraguay. In: Fronteras de la Historia, 9, Bogotá, ICANH, 2004. 
LAGARDE, Marcela. 1990 Los cautiverios de las mujeres: madresposas, monjas, putas, presas y locas. México: UNAM, 1997.

MONTOYA, Antonio Ruiz de. Conquista espiritual hecha por los religiosos de la Compañia de Jesús en las provincias del Paraguay, Paraná, Uruguay y Tape [1639]. Bilbao: Imprenta del Corazón de Jesús, 1882.

MORALES, Martín María S. J. A mis manos han llegado. Cartas de los PP. Generales a la Antigua Provincia del Paraguay (1608-1639), Madrid-Roma, Universidad Pontificia Comillas, Institutum Historicum Societatis Iesu, 2005.

. Los diarios de la transmigración y de la guerra guaranítica de Tadeo Enis y Bernardo Nusdorffer (1752-1756). Invitación a la lectura, In: KOHUT, Karl; TORALES PACHECO, María Cristina. Desde los confines de los imperios ibéricos. Los jesuitas de habla alemana en las misiones americanas. Madrid: Iberoamericana, 2007, p. 197-230.

O’MALLEY, John W. Los primeros jesuitas. Bilbao: Ediciones Mensajero, 1993. POUJADE, Ruth; GUTIÉRREZ, Carlos; AUSTRAL, Antonio; ROCCHIETTI, Ana. La política de las Misiones: el Coty - Guazú de Santa Ana, In: XII Jornadas Internacionales sobre las misiones jesuiticas. Interacciones y sentidos de la conversión, Buenos Aires, 23 al 26 de septiembre de 2008 [Versión PDF]

SEPP, Anton S. J. Continuación de las labores apostólicas. Edición critica de las obras del Padre Antonio Sepp SJ. A cargo de Werner Hoffmann, II. Buenos Aires: Eudeba, 1973. TOLEDO, Francisco de. Ordenanzas generales para la vida en común en los pueblos de indios (Arequipa, 1575). In: Disposiciones gubernativas para el Virreinato del Perú. 1569-1574. Sevilla, Escuela de Estudios Hispanoamericanos, v. I e II, 1989. WILDE, Guillermo. Orden y ambigüedad en la formación territorial de Río de la Plata a fines del siglo XVIII. In: Horizontes Antropológicos v. 9, n. 19, Porto Alegre July 2003. Disponível em: http://www.scielo.br/scielo.php?script=sci_arttext\& pid=S0104-71832003000100005.

. Religión y poder en las misiones de guaraníes. Buenos Aires: SB, 2009.

Recebido em: 27/10/2011.

Aprovado em: 17/01/2012. 